\title{
Reaching Students in Online Courses Using Alternative Formats
}

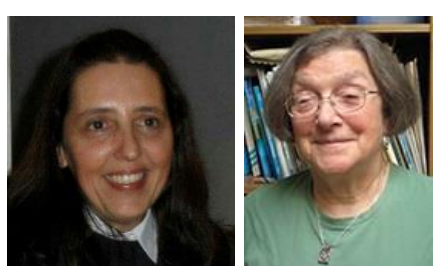

Patricia Fidaldo and Joan Thormann

Emirates College for Advanced Education, Abu Dhabi, UAE, Lesley University, Cambridge, MA, USA

\begin{abstract}
This research was conducted to explore whether students enrolled in graduate level courses found some Universal Design for Learning (UDL) strategies useful and if they actually used them. The strategies we investigated were presenting course information in alternative formats including PowerPoints with voiceover, screencasts, and videos as an alternative to text resources. In addition, students were invited to submit assignments in alternative formats as well as text. To examine these strategies, we used a student questionnaire, analytics from Blackboard, and assignment formats students used. The results indicate that text was the preferred format for accessing course information and resources as well as assignment submission. However, a substantial number of students acknowledged the benefits of using alternative formats and a smaller percentage used them. We suggest that instructors take advantage of UDL strategies that were examined since a sufficient number of students used them and because learning styles differ. We can reach more students by using these strategies.
\end{abstract}

Keywords: Universal Design for Learning (UDL), elearning, learning styles, multiple means of representations, alternative formats

\section{Introduction and Background}

Online learning is rapidly expanding in the educational setting. In this context it is important to investigate teaching methods that address diverse learning styles. While it is always challenging to create a learning environment that meets all students' learning needs, it can be even more so in an online course. In our experience, and that of colleagues, we have found that because we do not have the visual and physical cues that are present in face-to-face classes, we need to deliberately seek out feedback from online students to ascertain that we are reaching them.

Use of Universal Design for Learning (UDL) can support classroom learning for students with special needs (Morgan, 2015) as well as meet various learning styles of typical learners (Rose \& Meyers, 2002). 


\section{Reaching Students in Online Courses Using Alternative Formats \\ Fidaldo and Thormann}

In an online setting, UDL means that students are provided with multiple ways of accessing information (Dahl, 2005; Thormann \& Zimmerman, 2012) and multiple ways of demonstrating what they have learned (Passman \& Green, 2009; Thormann \& Zimmerman, 2012).

UDL involves providing students with access to information and demonstration of their knowledge and skills in a flexible way. It also creates an environment that reduces barriers. The theoretical framework of UDL is based on neuroscience which indicates that there are three major brain networks that support learning. They are recognition, strategies, and affective. To implement these networks UDL recommends that multiple means of representation are available, diverse ways for students to share their knowledge and engage students by giving choices (Center for Applied Special Technology [CAST], 2014).

This study focuses on some of the recommended UDL strategies including presenting course information in diverse formats and inviting students to submit assignments in alternative formats as well as text. These strategies were selected as a means of learning more about students' perceptions as well as the actual use of these strategies. All aspects of UDL were not included in an effort to isolate and determine if specific aspects make a difference for some students. All UDL guidelines could not be included in this study; however, additional principles were provided such as reflection, expectations, activation of background knowledge, goal-setting, and many more (CAST, 2014).

\section{Literature Review}

Various studies have been conducted relating to the implementation of UDL. Baldiris, Silvia, Panagiotis, Ramon, \& Demetrios (2016) found that through professional development when using UDL principles teachers "demonstrated a considerable amount of growth between pre-test and post-test when designing an inclusive lesson plan" (p.24).

A theoretical paper by Chita-Tegmark, Gravel, Serpa, Domings, and Rose (2011-2012) suggests that use of a UDL framework can help to enhance learning for culturally diverse students. With the growing number of virtual schools and concerns about accessibility of online materials Hashey and Stahl (2014) present resources to evaluate accessibility. Concrete strategies to incorporate UDL for students enrolled in online courses are presented by Tobin (2014). Using some UDL strategies can enhance learning for a wide range of students.

Incorporating time consuming UDL strategies seems like a good idea. However, Edyburn (2010) observed that most of the literature concerning UDL is based on expert opinion and praxis. Thormann (2013a, 2013b) and Scott, Temple, \& Marshall (2015) conducted research that provides some evidence that students view UDL strategies as useful in their online learning experience. Thormann also found that using alternative formats to present material increased the preparation time as well as the amount of time it took to evaluate assignments. Other research conducted by Scott et al. (2015) concluded that use of UDL principles in online courses may positively impact their learning.

UDL offers the opportunity to maximize online learning through the challenges it provides (Dell, Dell, \& Blackwell, 2015). In a study conducted by He (2014), in which online students reflected on the pedagogical methods to support learners with different levels of technology readiness and found UDL 


\section{Reaching Students in Online Courses Using Alternative Formats Fidaldo and Thormann}

quite valuable. On the other hand, Higbee, Lee, Bardill, and Cardinal (2008) who also conducted a study about UDL in an online course also from the perspective of the students, found that UDL is an effective model to engage students and to deal with students from different cultural backgrounds.

Evans (2008), concluded that UDL increases the positive learning outcomes of students by supporting each individual. Another aspect that is embedded in the UDL approach that emerged was that there is a relationship between students' preferred learning styles and their use of alternative formats. Findings of a study concerning students' selection of an online versus face-to face course based on learning styles showed there was no statistically significant difference (Rogowsky, Calhoun, \& Tallal, 2015; Zacharis, 2011). This study also found no difference in course performance. Using the Felder-Soloman's learning style inventory, Saeed, Yun Yang, and Sinnappan (2009) found that students learning style influenced the instructional technology tool they preferred. The results of these studies are mixed. This may be,in part, due to using different instruments to assess learning styles.

For over two decades, U.S. schools and universities must comply with laws that require access to education including access by those students who have print disabilities (Senge \& Dote-Kwan, 1995). Online educators generally agree that providing content in multiple formats (Moorefield-Lang, Copeland, \& Haynes, 2016) can address various student learning styles (Thormann \& Zimmerman, 2012; Vásquez, 2005).

\section{Methodology}

This study addresses the need to have more research-based evidence of whether or not alternative formats for resources and assignment submission are used by students and if these strategies are perceived by students as helpful in online courses. As the use of online teaching and learning increases (Allen \& Seaman, 2013) the opportunity to incorporate greater accessibility and accommodate to students' learning needs by using the theoretical framework of neuroscience and UDL is important to examine. It is also necessary to ascertain the efficacy of using these adaptations. Determining students' preferences and use can provide guidelines for online courses. This research can contribute to strategies that instructors in open and distributed learning can use to promote student learning.

\section{Research Questions}

Our research questions include the following:

- Which alternative formats do online students prefer to use to learn content? Why?

- Is there a relationship between the students' preferences about alternative formats and the course content?

- Which alternative formats do students view more frequently?

- When given the option to use alternative formats for submitting assignments what do students choose to do?

Based on UDL principles, different formats were selected to deliver course content in multiple ways and students were allowed to submit their assignments in alternative formats. We did not incorporate all 


\section{Reaching Students in Online Courses Using Alternative Formats \\ Fidaldo and Thormann}

UDL principles in this study but only focused on use of alternative formats for directions, overviews, and content. This study was conducted to help build research based evidence to the claims that UDL principles such as use of alternative formats are beneficial for students with and without special needs. UDL has an inclusive nature that can enhance the experience of all online learners (Van Rooij \& Zirkle, 2016). The idea of using alternative formats is not new (Thormann \& Zimmerman, 2012; Vásquez, 2005); however, few studies have been conducted from the student's perspective.

\section{Setting}

This research was conducted in two, 8 week, online, graduate-level courses offered in the Fall of 2014 and Spring 2015. Blackboard was the learning management system (LMS) that was used. The 2014 course was Online Teaching: Course Design, Development, and Strategies, which is the capstone course in a five-course Advanced Professional Certificate (APC) in Online Teaching. This course provides the opportunity to synthesize components of online teaching by involving participants in the development of an online course.

The Spring 2015 course was Online Teaching: Introduction to Design and Practice, the first course in the certificate sequence. This course is designed to introduce online teaching to educators. Using a constructivist learning approach, we explore the pedagogy and best practices for teaching and learning online. Aragon, Johnson, \& Shaik (2002) wrote that the way learners receive and process information is what makes them have different learning styles. We use this broad definition of learning style and operationalize it in presenting course content to include various formats including text, PowerPoint (PPT) with voiceover (visual and auditory), YouTube videos (visual and auditory), and screencasts. The text used in the PPT was exactly the same as the text only option. The voiceover consisted of reading the PPT text which could be turned on for each slide if the student chose to do so. An overview of the week was presented in a screencast with a graphical PPT and the instructor reading the text in the Fall 2014 course. In the Spring 2015 course, both text only and screencast overview formats were offered. Both classes had screencasts but only one had both text and screencasts. In addition, two resource formats were available; one with articles relating to the weekly content and the other with YouTube videos relating to the content. The YouTube video presentations varied. Typically for each assignment students were required to read two articles and/or view videos. Essentially alternative formats presented the same content as the traditional text format.

In the first weeks of both the courses the focus was on introductions and ice-breaking activities and thus there were no articles or videos. Students were invited to submit their assignments in any format they chose. This allowed them to use their learning strengths in the assessment process. Expectations and rubrics for each assignment were shared in the directions and were the same for both text and alternative formats. The instructor evaluated each assignment (both text and alternative) and sent written feedback and a scored rubric. There were three overarching guidelines to submit assignments in an alternative format. The format needed to be easily accessible to everyone in the class, all components of the assignment included and APA citations used. These guidelines were communicated in the text, PPT, and in Skype meeting during the first 2 weeks of the course. During this Skype meeting, the instructor also pointed out that assignments and resources were available in alternate formats. 


\section{Reaching Students in Online Courses Using Alternative Formats \\ Fidaldo and Thormann}

\section{Participants}

There were nine students in the Fall 2014 and 18 students in the Spring 2015 course. One student in the Fall group completed only the first assignment, thus the total number of students completing the two courses was 26 , five male and 21 female. Most students were K-12 teachers from 11 U.S. states and one teacher from Asia, earning either their M.Ed. and/or an APC in Online Teaching.

Teachers were from all levels including elementary (11), middle (4), high schools (6), district-wide (4), and university (1). The subjects students taught covered most curriculum areas. Three students indicated that they had done some blended teaching, two others used an LMS with their students, one had done online tutoring, another had used flipped learning, and one was in the process of developing an online course. Eighteen of the 26 students responded to the questionnaire; six students in the Fall 2014 and 12 in the Spring 2015 course. This study did not focus on students with special needs. None of the students contacted the office of Disability Services to document a disability.

\section{Data Collection}

The methodology used for this study was mixed methods. An analysis of statistics gathered from Blackboard was performed. Alternative format data resided in a separate folder. This allowed us to access student usage data from Blackboard. A report with the "Number of Times Accessed" data was produced by the LMS. The Blackboard data and submission formats served as a means of observing students format preferences.

Another measure involved counting and listing the different ways students submitted their assignments in order to look at the frequency of text versus alternative formats. This was done by viewing each assignment that was submitted and noting what type of format was used.

In addition, a questionnaire was constructed and was completed after students finished their course and grades were submitted. The questionnaire asked which formats students preferred for understanding course assignments and course content, why they chose to submit assignments in a particular format, if the subject matter influenced their selection of the format, and if the varied formats helped them. We also asked what they consider their preferred learning style to be, in order to find out if their actual usage of the various formats was aligned with their stated learning style preference. The final question asked permission to use their responses for research purposes. For most of these questions we ask the rationale for their responses.

\section{Limitations}

The number of students enrolled in the courses determined the size of our study. The number of hits on each one of the resources available to the students does not provide information about if they actually read, listened, and/or saw those resources and its content. The students could have downloaded the files on their computers and there is no way to find out what they actually did with those files.

In the Fall 2014 course we developed and presented a weekly overview using a screencast only. In the Spring 2015 course, the overview was presented in a screencast format and a separate text format. Omitting text in the Fall 2014 class was an unintentional oversight. Both formats should have been available. 


\section{Reaching Students in Online Courses Using Alternative Formats \\ Fidaldo and Thormann}

\section{Ethical Considerations}

The course content and presentation was slightly altered for this research project. Most of the accommodations were used in previous courses. Questionnaires were sent to students after the course was completed and responding to the questionnaire was totally voluntary and anonymous. Students were not subjected to a course with an experimental design that might have negatively affected their learning or performance in any way.

\section{Results}

\section{Blackboard Analysis}

An analysis was done of the number of hits that each student performed on Blackboard on the assignment directions and available resources of the course in different formats. In the Fall 2014 course, the total number of hits per format was: 418 for text resources, 63 for PowerPoints, 12 hits for Screencasts, and 115 for videos (Figure 1).

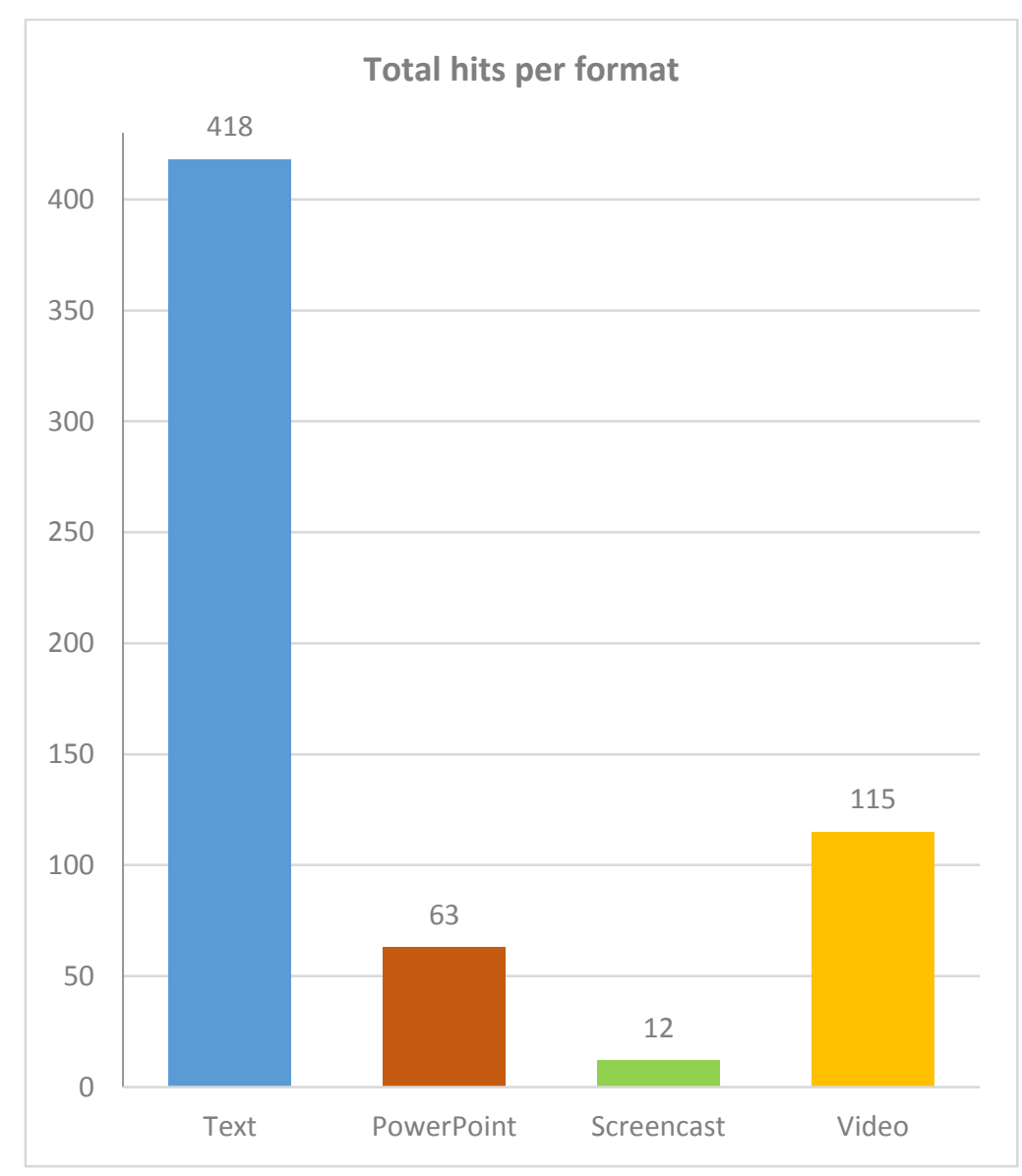

Figure 1. Fall 2014: Total number hits per format. 


\section{Reaching Students in Online Courses Using Alternative Formats Fidaldo and Thormann}

An analysis of the preferred formats for assignment instructions for Fall 2014 showed that text was the format with the most hits (Figure 2). The number of hits for text instructions was always much higher than for PowerPoints (63) or videos (115).

As can be seen in Figure 2, for all the assignments, text was the format with the most hits, while PowerPoints with voiceover had fewer hits. Videos about the content for assignments \#2, \#3, and \#6 were accessed more frequently than other assignments.

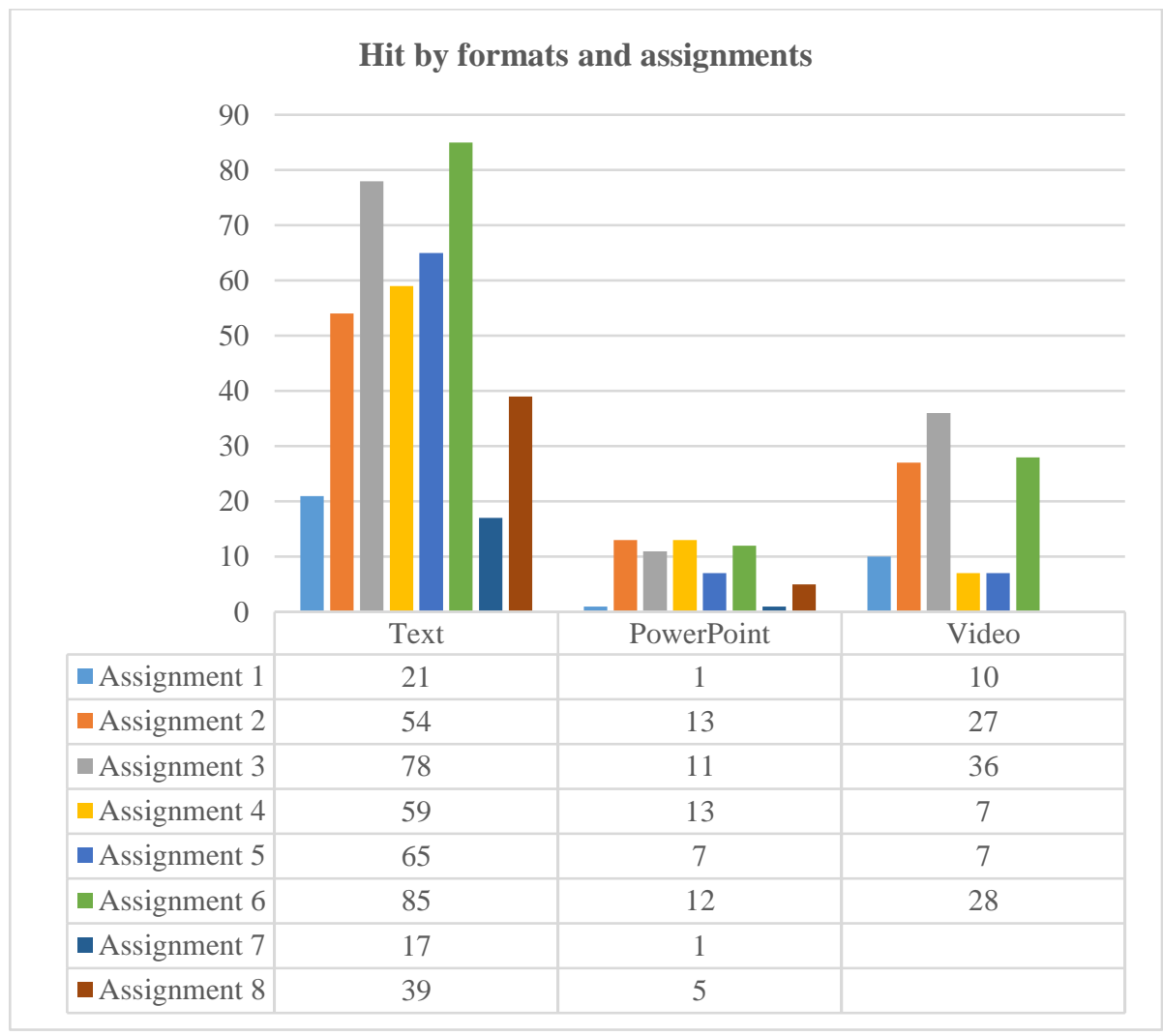

Figure 2. Fall 2014: Number of hits by formats and assignments.

An analysis was performed on the number of hits that screencasts had (Figure 3). On six of the seven assignments, the screencast only had one hit, while on assignment \#3, it had eight hits. This may have been because by the third assignment, the instructor specifically alerted students about the availability of the screencasts. 


\section{Reaching Students in Online Courses Using Alternative Formats \\ Fidaldo and Thormann}

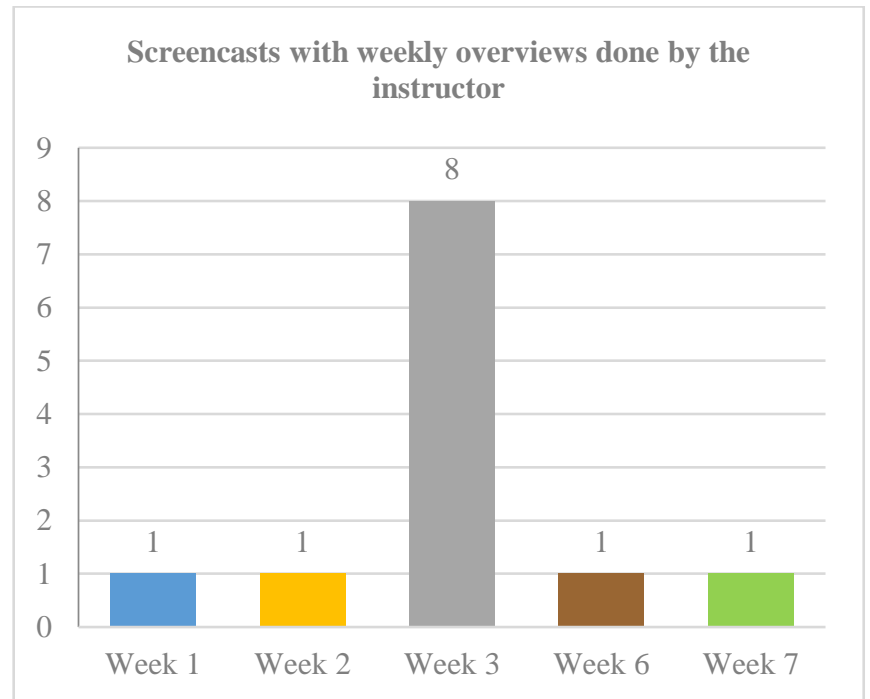

Figure 3. Fall 2014: Number of hits on the weekly screencasts.

The same three analyses were performed on the Spring 2015 course. The total number of hits per format was: 1485 for text resources, 107 for PowerPoints, 63 for Screencasts, and 580 hits for videos (Figure 4). Additionally, as with previous results, the text format had the highest number of hits.

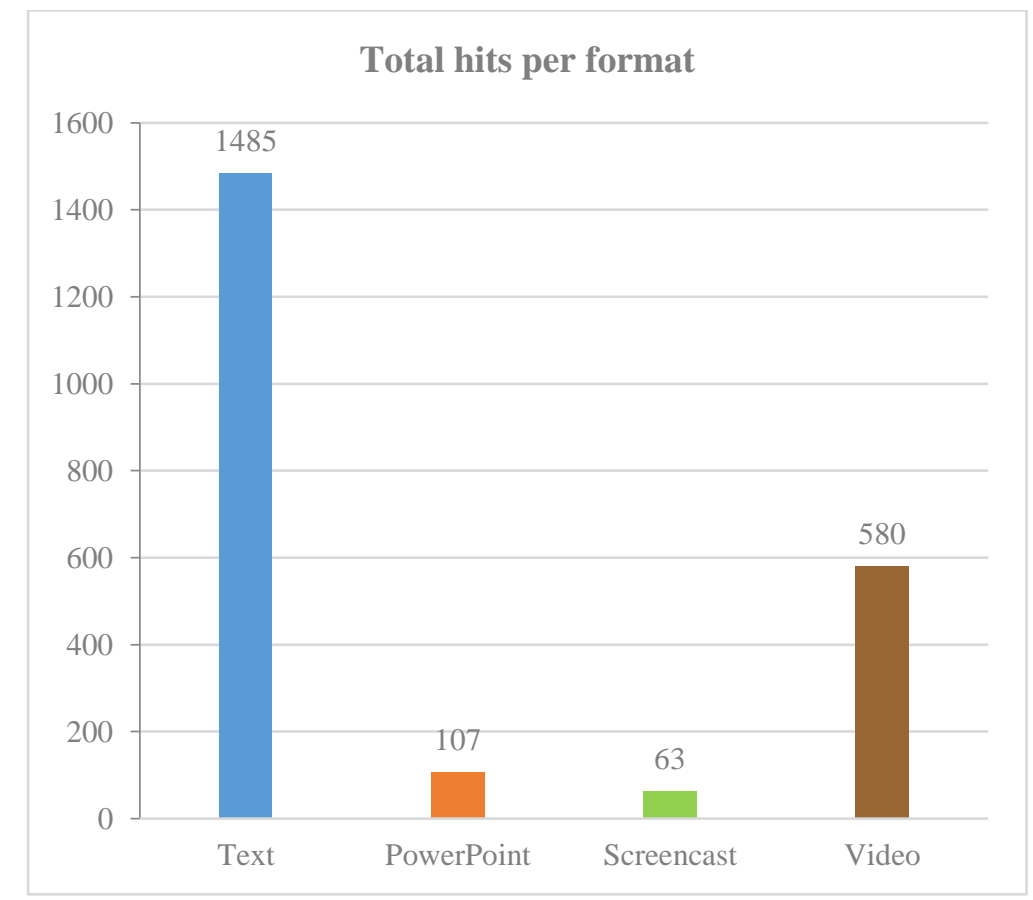

Figure 4. Spring 2015: Total number of hits per format.

An analysis of the preferred formats of the students to access the assignment instructions (Figure 5) showed that the text was the format with the most hits for almost all the assignments (except for assignment \#4). The number of hits for text instructions was always much higher than in the other formats. Assignments \#1, \#2, and \#5 did not have the video format as an option for students to consult. 


\section{Reaching Students in Online Courses Using Alternative Formats Fidaldo and Thormann}

Assignment \#4 had the greatest number of hits because students were required to view videos for this assignment.

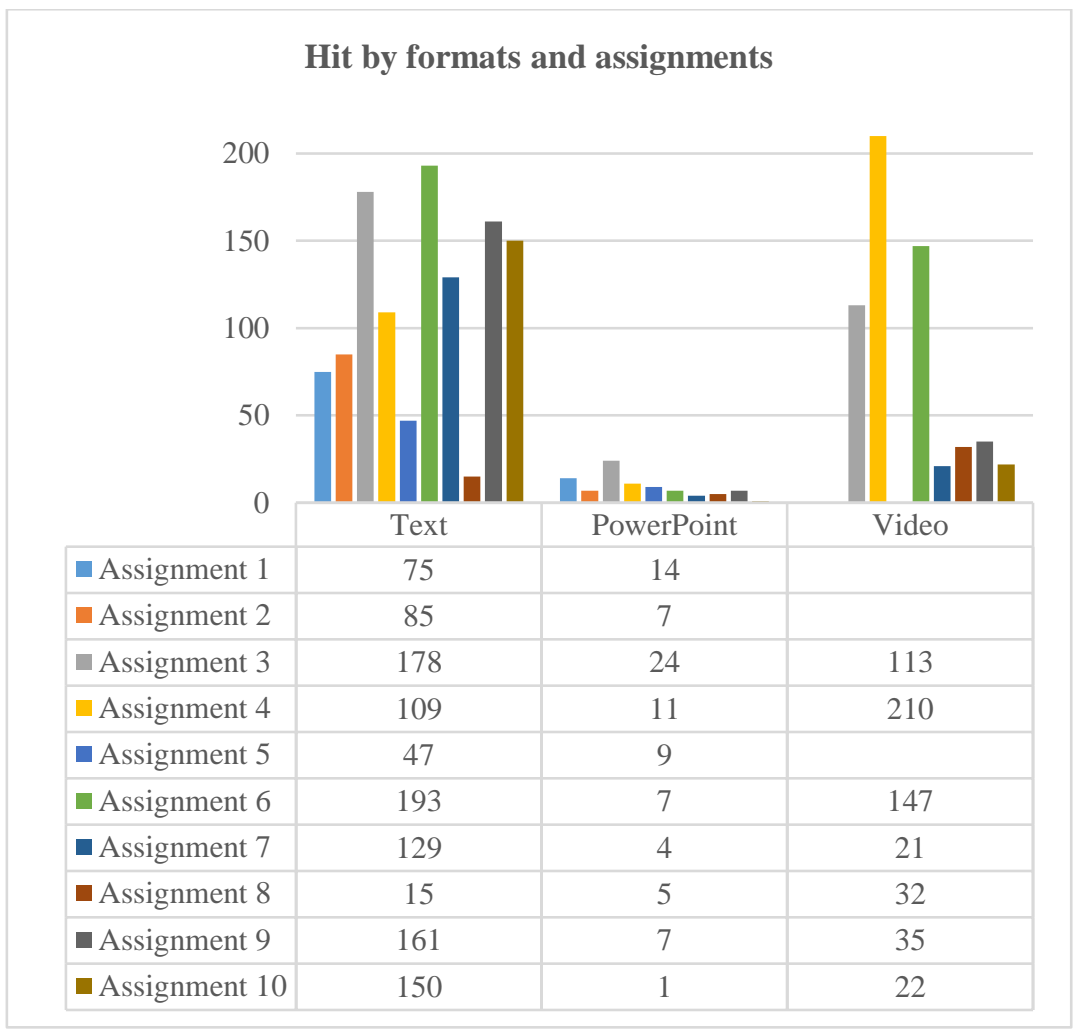

Figure 5. Spring 2015: Number of hits by formats and assignments.

For the Spring 2015 course, the instructor also made available screencasts of course content for that week as well as a text format. The results show (Figure 6) that the format with more hits was the text format, although both formats had a decreasing number of hits over the 8 week duration of the course (except for the screencast format in weeks 4 and 8 and for text in week 8 ).

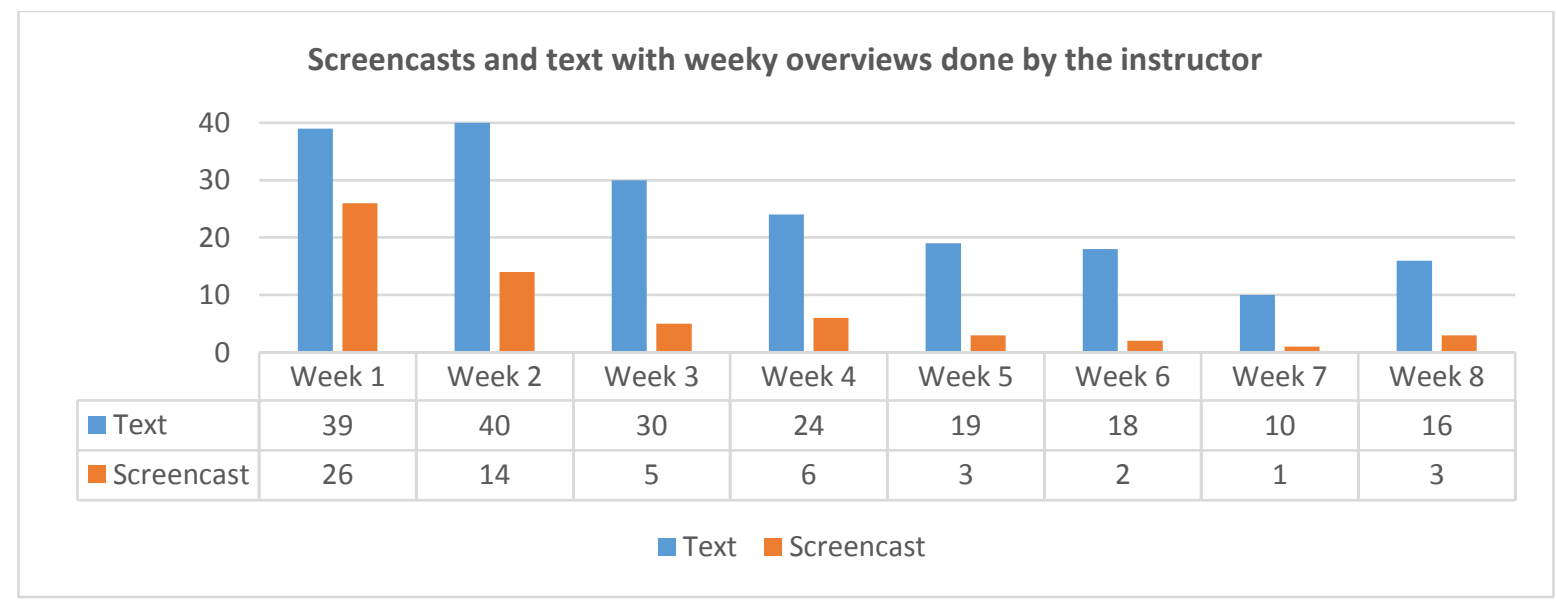

Figure 6. Spring 2015: Number of hits on the weekly screencasts and texts. 


\section{Reaching Students in Online Courses Using Alternative Formats Fidaldo and Thormann}

\section{Questionnaire}

The questionnaire had 10 questions. The first question asked students to rank their preferred formats for finding out what directions and background for the assignments were. Figure 7 shows that the text format was selected as their first choice by most of the students (78\%), followed by PowerPoint with voice over (16\%). The screencast format was the first choice of only one respondent (6\%).

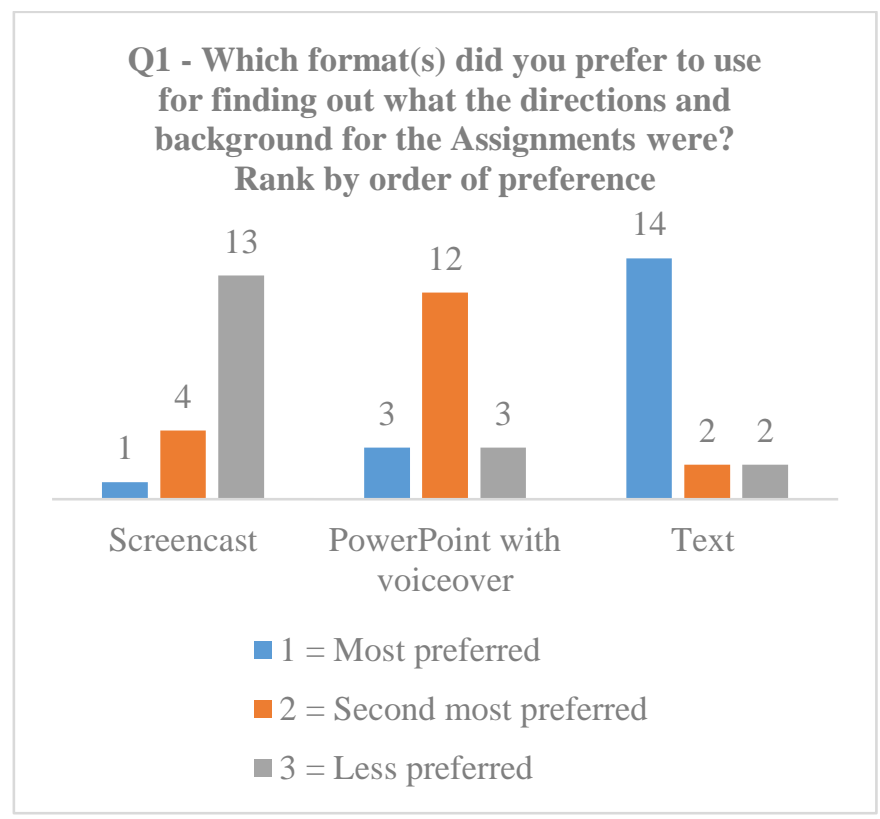

Figure 7. Preferred formats of the Fall 14 and Spring 2015 students.

The second question was open-ended, asking about the reasons for answers provided in question \#1. The students that chose text, gave responses such as, "With text, I had the expectations, instructions, and due dates all on one page in front of me. I could print it out if needed or just save it and refer back to it" or "I liked to print out the text and put in a binder that way if I was not near my technology and internet I was still able to access what work I needed to do for the week." Another respondent wrote "Having the text version of an assignment provides me with a sort of 'checklist' that I can easily reference to make sure that all parts of the assignment are complete." Regarding the preference for PowerPoint, one respondent wrote, "I used a combination of the text and the PowerPoint. Whenever there was too much text for my brain to process, I would look through the PowerPoint. Having the information broken up in slides helped sort out what was required of me." The preference for PowerPoint with voiceover was described by another respondent: "I work best when information is explained in chunks rather than all at once. Being able to have the PowerPoint separated the information into pages which helped me create a timeline of things to do."

The next question asked students which format they preferred to access course content with (i.e., articles and videos). Most students said they preferred YouTube videos (Figure 8). 


\section{Reaching Students in Online Courses Using Alternative Formats Fidaldo and Thormann}

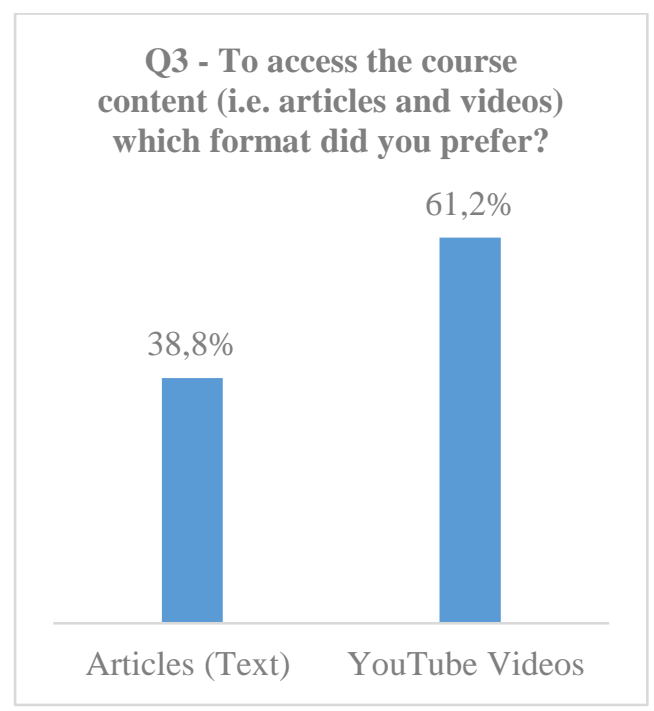

Figure 8. Preferred formats of the Fall 2014 and Spring 2015 students.

Figure 9 shows the answers to question \#4. Most of the respondents said the course content and subject matter did not influence them in the choice of format.

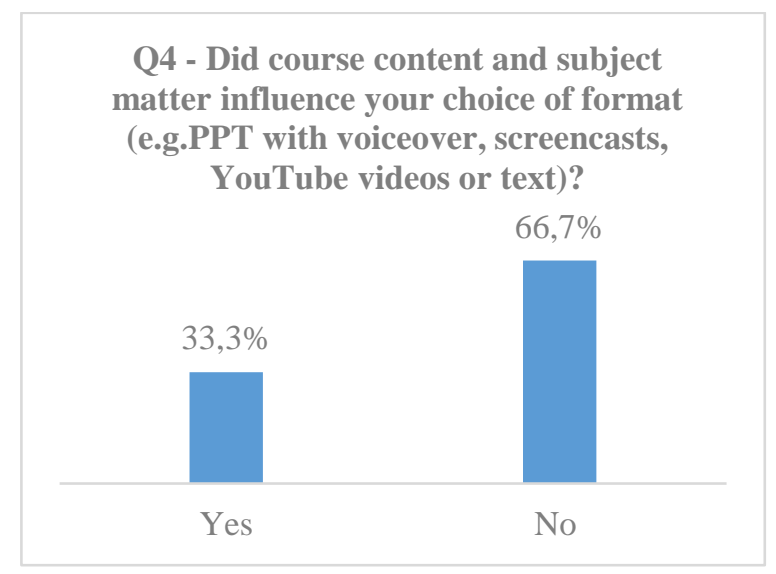

Figure 9. Fall 2014 and Spring 2015 influence on format choice.

Question \#5 was open-ended and inquired about students' reasons for their response to question \#4. Ten students responded that the course content and subject matter did not influence them. "This was more about my preferred learning style than it was about the content or subject matter" stated one of the respondents, while another wrote "I somehow found the articles that had long research to have a lot of extraneous information and that the videos were more tailored to the learning." Eight respondents that answered "yes" presented comments such as, "I needed the information in a quick and easy format to refer back to easily as a checklist for this course" and "I like to be able to back up when I need to understand key points."

Question \#6 was also open-ended and asked about the preferred format for submitting assignments and the reasons for that choice. Most of the respondents said they preferred the text format although the reasons varied. "I preferred text, but if I was not working full time, I would have used the other formats for sure," while another responded, "Text just because that is what I was used to from other 


\section{Reaching Students in Online Courses Using Alternative Formats \\ Fidaldo and Thormann}

classes." Another student wrote, "If time allowed, I always like to use presentation tools like Prezi and VoiceThread. However, with my time constraints during the class, I used word/text mostly." Another respondent shared the following, "Text. Easier to get my point across. Less time consuming." One student indicated that he/she doesn't have a preference: "I like to try a lot of different options so that I know what tools are out there and how to use them." Other students did some experimentation regarding the formats; "Initially I preferred regular text format, but as we progressed through the class I thought it would be a nice challenge to use alternate means of presenting the assignments" wrote one of the students, while another wrote "I tried to use technology that I didn't know much about so I was able to learn by learning. :) I know how to use Word well, but I felt being able to know how to use other technologies would allow me to understand the challenges my students may have."

Question \#7 asked respondents to indicate their degree of agreement by completing the statement, "I found having assignment directions, some resources and being able to submit work in alternative formats..." As show in Figure 10, most of the students found it very helpful to have assignment directions, some resources, and being able to submit work in alternative formats while three students found it somewhat helpful.

\section{Q 7 - I found having assignment directions, some resources and being able to submit work in alternative formats}

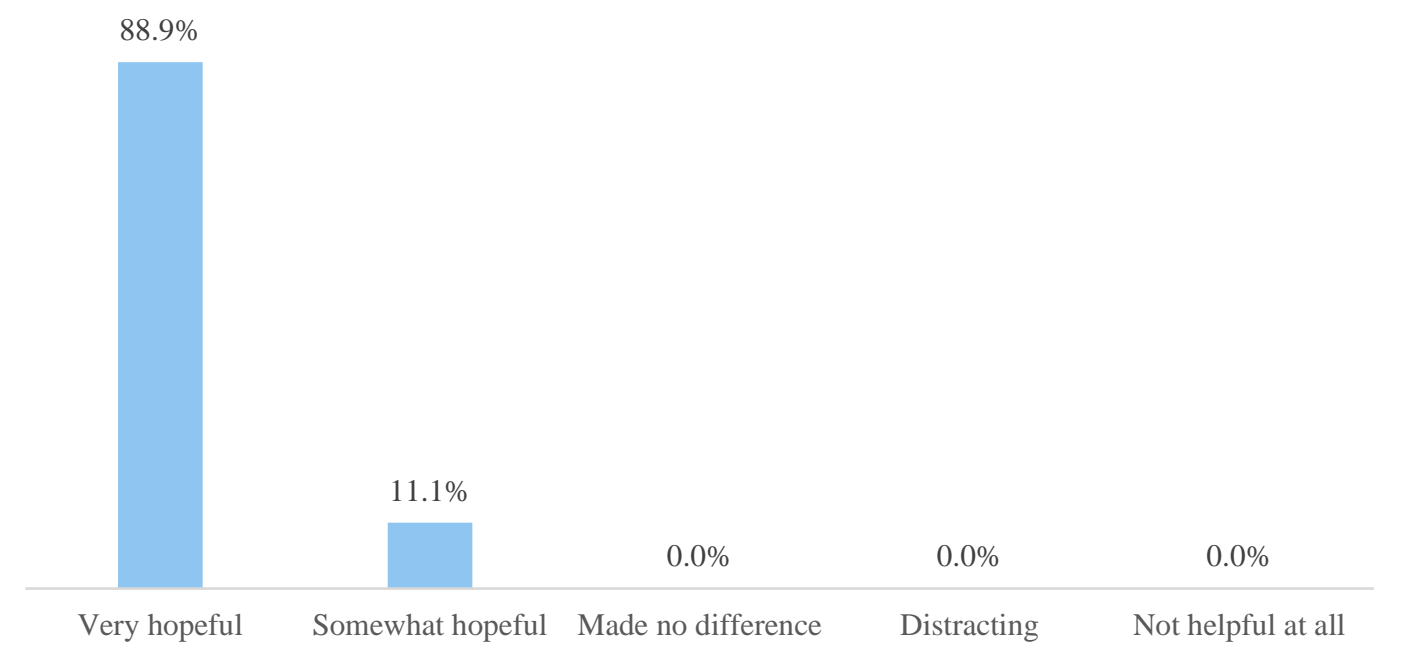

Figure 10. Opinion of the students from the Fall 2014 and Spring 2015 courses.

Question \#8 was open-ended and asked students about what other formats might have been helpful for presenting assignment directions and background and resources. Just one of the respondents shared another format (podcasts). The remaining answers referred to the formats used by the instructor during the course. "Due to the content of the course, I believe the 3 best choices were used to cover visual and audio learners," wrote one student, while another wrote "I think that the variety that was offered was good. Not overwhelming, but allowed for choices."

Finally, question \#9 asked students what was their preferred learning style. Respondents could choose more than one option. Almost all respondents indicated that they were visual learners, with a few 


\section{Reaching Students in Online Courses Using Alternative Formats \\ Fidaldo and Thormann}

indicating they were kinesthetic, and only four identifying themselves as auditory learners. Eight of the respondents chose more than one learning style (Figure 11).

It should be noted that during a one-to-one Skype meeting with each student, the instructor discussed learning styles with them. Three different learning style inventories were available. Almost all students did at least one inventory, while some did all three. Most students indicated that the inventory confirmed what they thought their learning style was. This provided us with an informed self-report.

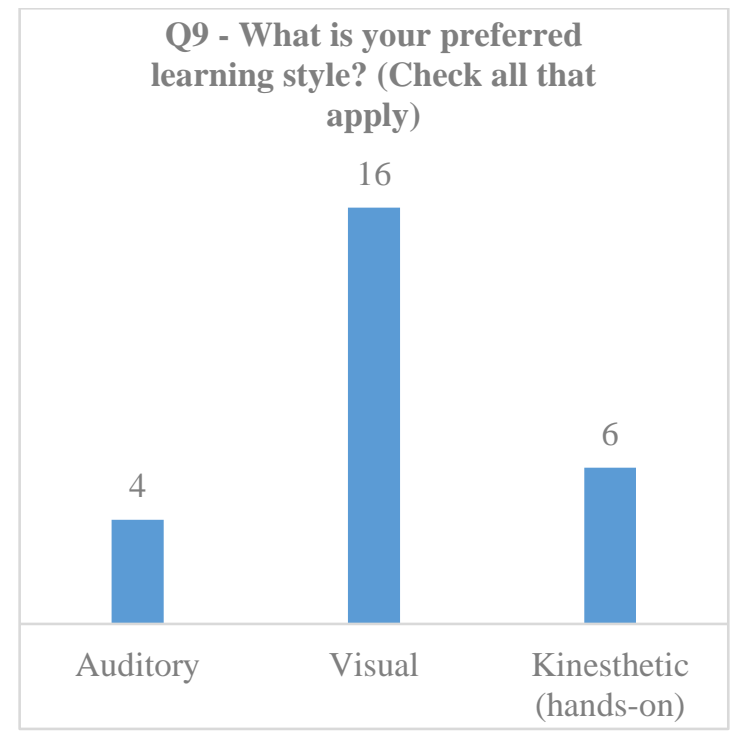

Figure 11. Students preferred learning style.

\section{Assignments}

The instructor offered students the option of submitting their assignments in whatever format they chose. In the Fall 2014 group, there were a total of 88 opportunities to submit assignments. Forty-one percent of the assignments were submitted in an alternative format, while $59 \%$ were submitted in text (Figure 12). There were a total of 144 opportunities to submit assignments for the Spring 2015 group, $27 \%$ were in an alternative format and $73 \%$ were in text (Figure 13 ). 


\section{Reaching Students in Online Courses Using Alternative Formats \\ Fidaldo and Thormann}

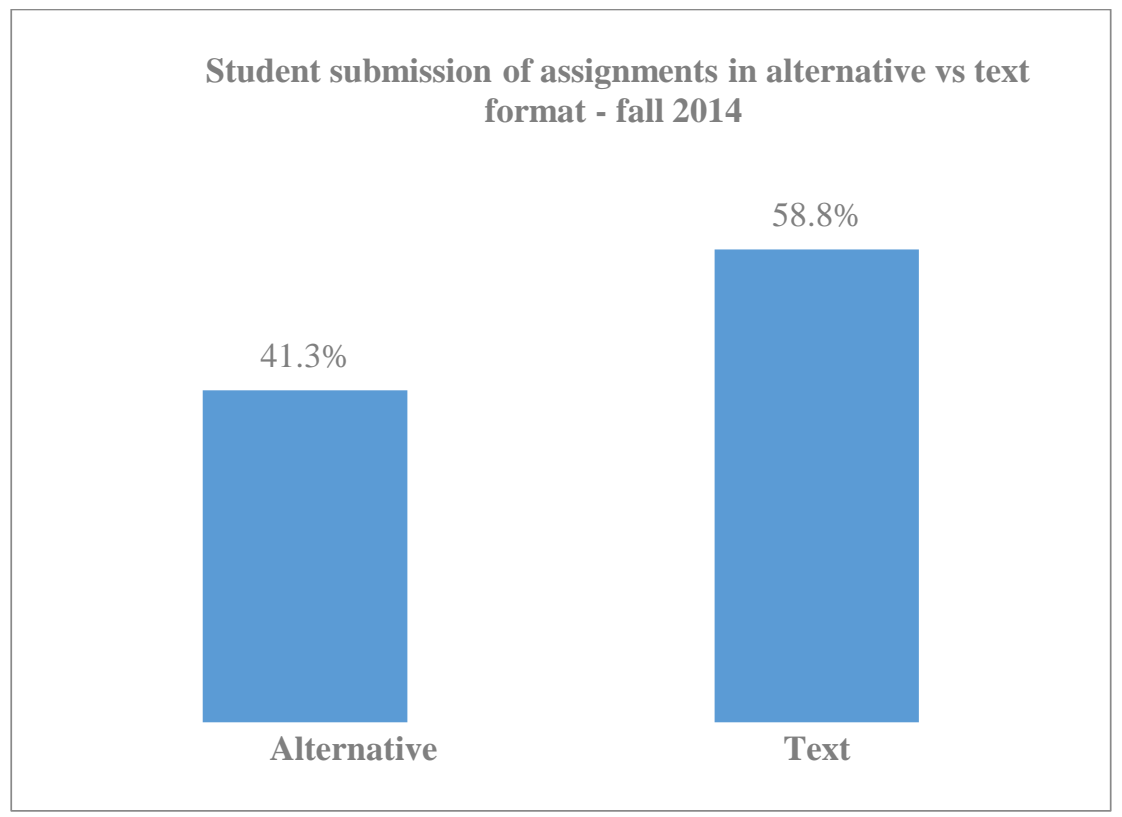

Figure 12. Student submission of assignments alternative vs. text format.

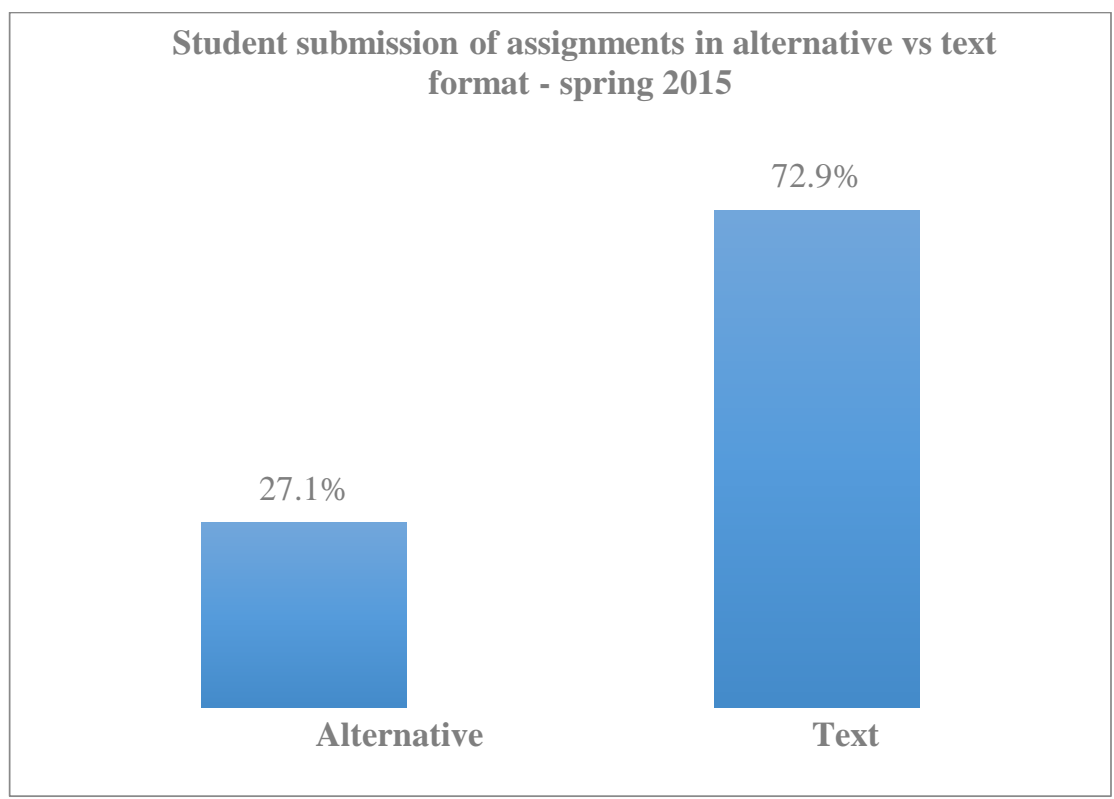

Figure 13. Student submission of assignments alternative vs. text for5mat.

Students used a variety of alternative formats as indicated in Figures 14 and 15. 


\section{Reaching Students in Online Courses Using Alternative Formats \\ Fidaldo and Thormann}

Alternative assignments submitted

Fall 2014

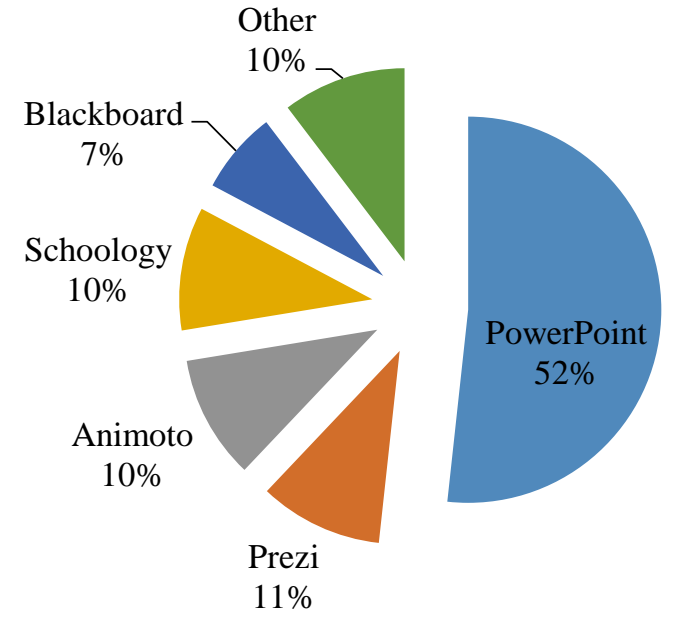

Figure 14. Fall 2014: Alternative formats used.

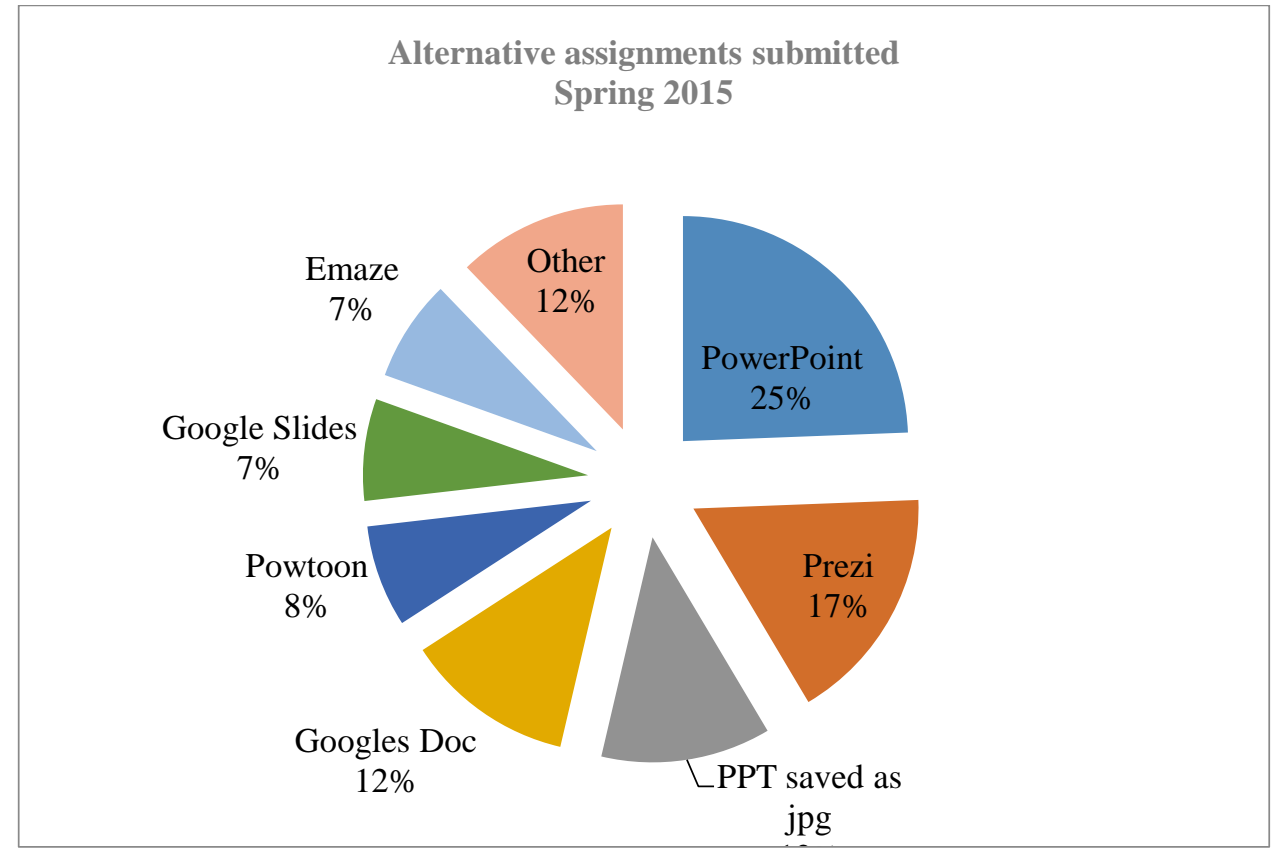

Figure 15. Spring 2015: Alternative formats used.

The most used alternative formats can be categorized as slideshows with PowerPoint being the most frequently used. Figures 16 and 17 show how many assignments were submitted in an alternative format for each assignment. It should be noted that for some assignments either students were not asked to submit it for assessment (e.g., Skype meetings or selecting partners) or the format of the assignment was prescribed. These assignment numbers are not shown because they are not applicable. 
Reaching Students in Online Courses Using Alternative Formats

Fidaldo and Thormann

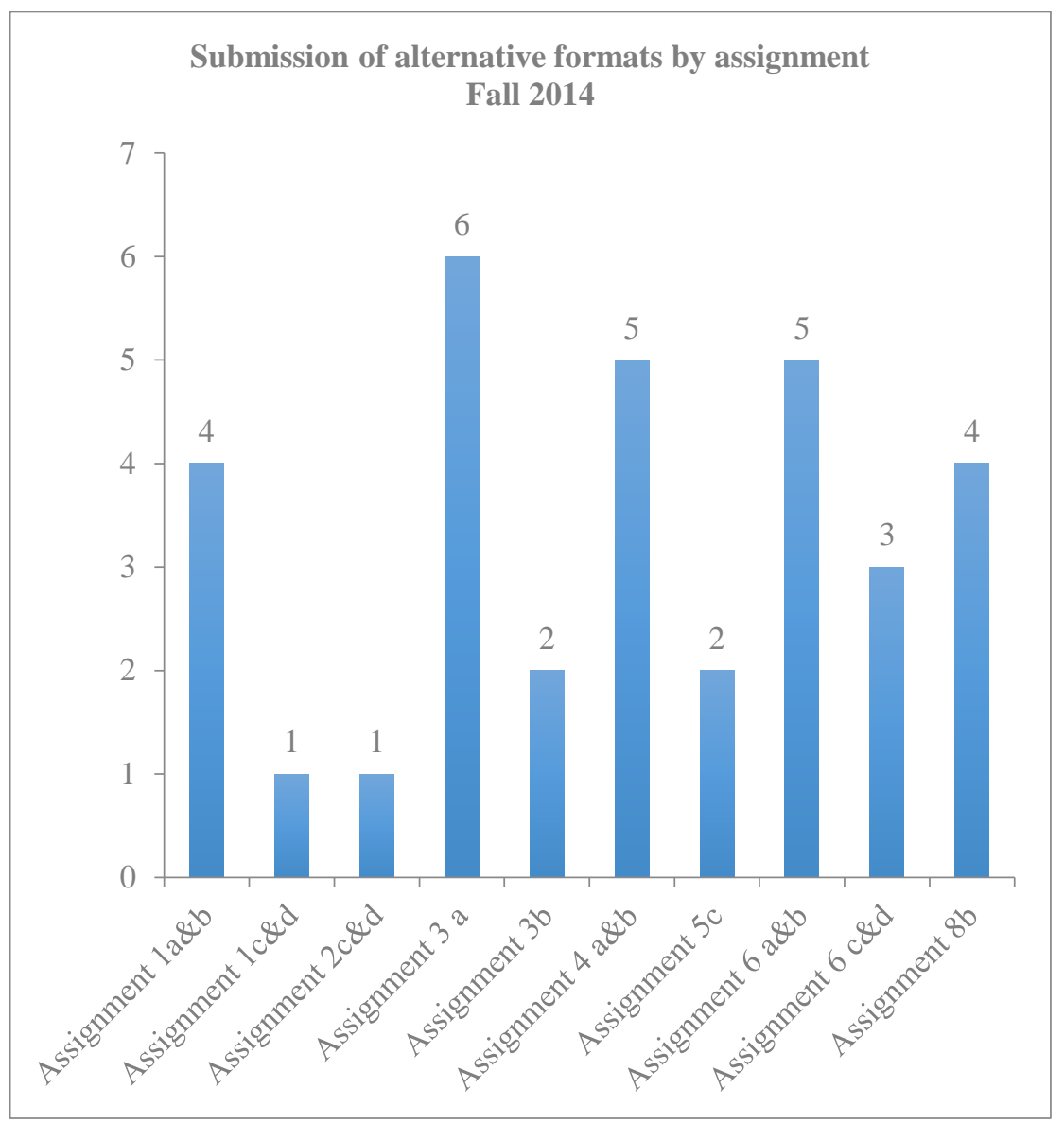

Figure 16. Fall 2014: Submission of alternative assignments by assignment. 


\section{Reaching Students in Online Courses Using Alternative Formats Fidaldo and Thormann}

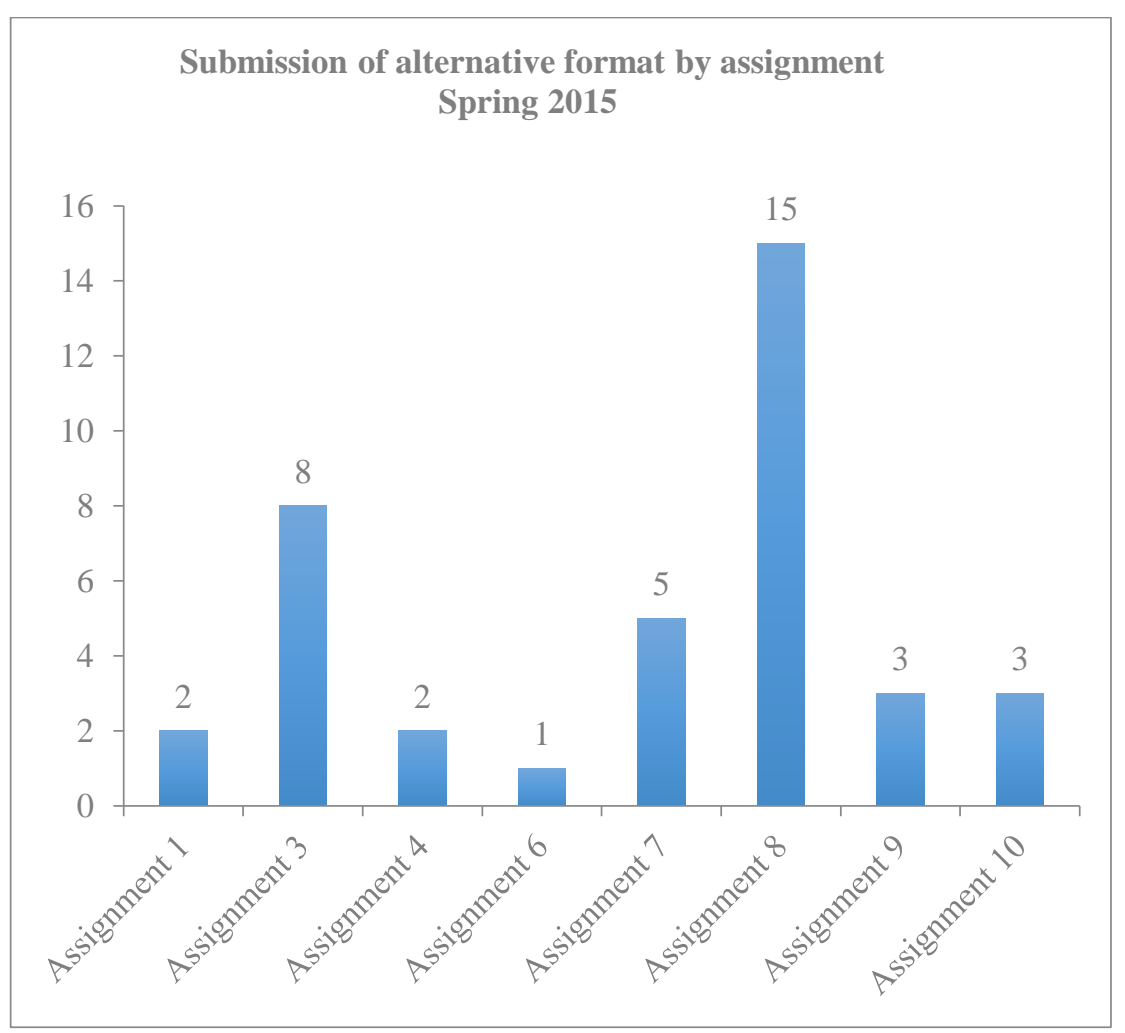

Figure 17. Spring 2015: Submission of alternative format by assignment.

As shown in Figures 16 and 17, some assignments were submitted in an alternative format more frequently. During the Fall 2014 class, 50\% of the assignments were submitted in an alternative format. In the Spring 2015 class, only two assignments (\#3 and \#8) stand out as being submitted in an alternative format by a substantial number of the 18 students (\#8 and \#15 respectively).

\section{Discussion}

The questionnaire data clearly show that most students in these classes preferred a video format when viewing content in order to learn content. This supports the data which indicate that most of the students describe themselves as visual learners. This does not mean that text should not be used since there were a substantial number of students who preferred and used text. In order to maximize learning, when designing a course, different learning styles should be taken into account and different formats for presenting the content should be made available.

From an instructor's point of view, there are a number of dilemmas attached to using visual or video material for teaching. It is difficult to find materials that communicate the breadth and depth of knowledge that is available in text format. It is a daunting task to find high-quality, engaging video presentations in a particular content area. Making one's own videos that work well is beyond many individual instructors' capabilities. Nevertheless, even with these limitations, many students in these classes found the video option preferable.

The Blackboard data on actual use of alternative formats for viewing assignment directions showed that both groups used PowerPoint a small percentage of the time ranging from 19\% (Assignment \#1) to 1\% 


\section{Reaching Students in Online Courses Using Alternative Formats \\ Fidaldo and Thormann}

(Assignment \#10) for the Spring 2015 group. The Fall 2014 group also used PowerPoint similarly ranging from 24\% (Assignment \#2) to 1\% (Assignment \#1) of the time. The Blackboard data is somewhat contradictory to the questionnaire data in which most students indicated that the alternative formats were very helpful and that PowerPoint was preferred as a second choice. However, the responses to the open-ended questions about this reveal that a good number of students wrote that while alternative formats were not necessarily useful for the person who wrote the response, it was a good option to have available. It should be noted that most students enrolled in these graduate courses had only started taking online courses with this M.Ed. and certificate program. In addition, most if not all have not been exposed to having the option of using alternative formats previously and indicated it was more time effective to read the text assignments. Because these students have only experienced using text for assignment directions, viewing, and listening to text read (PowerPoint with voiceover) may have been out of their comfort zone.

The Blackboard data showed that the use of videos for content resources was considerably higher than the use of PowerPoint but that videos were still accessed less frequently than the text. A possible explanation as to why the text was accessed more frequently is that the videos were listed in a separate folder while the text resources were listed along with the assignment directions. In such circumstances a true comparison cannot be made. However, it is interesting to note that for the Spring 2015 group, Assignment \#4 required that students view videos, as well as, text resources. Video viewing was not optional. In this case the videos were accessed almost twice as often as the text.

Since text resources in both courses were accessed more often than videos, it is fair to ask why $64 \%$ of the students that responded to the questionnaire indicated that they preferred the YouTube videos over the text resources and almost all reported that they were visual learners. This inconsistency may be because having gone through many years of text-based learning, graduate students are more comfortable with the text mode. A small portion ventured to use the videos. Another factor may be that often the text contains more in-depth information. Even though the videos that were selected were purposely chosen for containing parallel content that was engaging and in a relatively short presentation, students may have felt that they would lose some content by choosing videos. This may be a focus for additional research.

A screencast with an overview of the week was offered each week for both courses. In the Fall 2014 course, for every week except for week 3, the screencast was accessed only once or not at all. One explanation is that at the end of the second week the instructor had completed the one-to-one Skype meetings during which she mentioned all the alternative formats. Students may have accessed the screencast in the third week to find out what it had to offer, and then most may have decided they did not want to use them. For the first two weeks, the Spring 2015 group started out accessing both the text and screencast versions of the overview; however, both were accessed less frequently as the course proceeded. The screencast viewing dropped. Students may have found it more efficient to read the overview than to listen and view slides. It is unclear what the screencast option may have contributed to the overall course experience and whether they were worthwhile developing. The question that may be asked is if one or a few students access them and potentially benefit from them, should they be included as an alternative? This may be a focus for additional research.

In the questionnaire, students shared that there was some relationship between the participants' preferences about formats and the course content. One third thought that it influenced their choice of 


\section{Reaching Students in Online Courses Using Alternative Formats \\ Fidaldo and Thormann}

formats and two thirds did not. Comfort level with a particular format and learning styles seem to have influenced their choice. When teaching a course it is helpful to note that not all students learn the same way. The goal is hopefully to reach all students. Even though many students did not think content influenced the format, students indicated that various formats should be available.

Students were given the option to use alternative means of submitting their assignments. A substantial number of students submitted their assignments in an alternative format. Twenty-seven percent of the assignments in the first class of the certificate program and $41 \%$ of all assignments in the capstone certificate class were submitted in alternative formats.

The questionnaire responses indicated that there was an almost unanimous approval of being allowed to submitted assignments in alternative formats. In addition, a larger percentage of assignments were non-text in the capstone class than the initial certificate class.

We speculate that this difference is based on a number of factors. As graduate students, many were most comfortable with submitting their assignments in a traditional text format. Although enrolled in a technology program, using a different format may have meant spending more time doing their assignments. Some students may have found it easier to do what they are familiar with due to time constraints. They, in principle, approved of this idea but may have found it difficult to select an alternative tool to use and then re-conceptualize how to approach the assignment. The most popular tools chosen were PowerPoint and Prezi which are tools that are well known. This may have helped students avoid the problem of selecting a tool. Most went with what they knew and were comfortable with.

The fact that a greater percentage of students in the capstone certificate class chose the use of alternative tools may have been due to having taken more courses and, because of that, they might have been more knowledgeable and comfortable with using alternative tools at end of the certificate or M.Ed. program.

For those that chose to use alternative formats, they may have been more comfortable since it may have matched their learning style better. In addition, some students, even at the graduate level, dislike writing. Some students may appreciate doing assignments in a variety of ways and enjoy experimentation. When an interesting format was used by some students, positive comments from classmates were often posted on the discussion board. This peer approval may have influenced some to venture into use of alternative formats or continue using them.

The question still remains as to why almost all students indicated that submitting assignments in an alternative format was very helpful. The answer may be that this freedom opens up possibilities and allows students to experiment with different formats, as well as, challenged some students to learn new presentation tools. There were a number of instructional technology specialists in the class and often they were the students who used alternative formats the most. Another factor may have been that those who used the alternative format just found it more interesting to do this than submitting text. This may be a focus for additional research. 


\section{Reaching Students in Online Courses Using Alternative Formats \\ Fidaldo and Thormann}

\section{Recommendations}

When teaching online courses, much planning needs to occur (Cook, 2012; Sims, Dobbs, \& Hand, 2002; Thormann \& Zimmerman, 2012). Although experts in the field recommend that UDL strategies should be used there is little research concerning students' preference (Edyburn, 2010). This research concerning students' format preferences may help to determine whether some UDL principles should be incorporated in course development. Our data lead us to recommend the following:

- Use alternative formats to present both course content and assignment directions to support different learning styles;

- Use videos and other visuals to support students since most report that they are primarily visual learners;

- Offer students the opportunity to submit assignments in an alternative format to meet various learning styles and to challenge students; and

- Use alternative formats to serve as a model for promoting better learning and as an opportunity to satisfy the different learning styles.

Conducting additional research regarding student perceptions and use of alternative formats with a larger number of students in online courses would be helpful. The perspective of faculty who teach online could also be examined. Other UDL strategies should be evaluated at all levels in the online environment. All of this suggested research might also be conducted in traditional or blended classroom settings.

\section{Conclusion}

Although the number of participants in this study was small and not all students prefer using alternative formats, this option should be made available so that online instructors are able to reach a wide range of students. This research confirms that use of alternative formats which are components of UDL strategies have validity as perceived by students and also extends into students' practice. While the students preferred text, videos were accessed and preferred by a substantial portion of the students. Videos were the alternative formats students viewed most frequently. Course content did not seem to impact student alternative format preferences. PowerPoint was the most frequently used alternative format for submitting assignments but alternative submissions were less prevalent than text. This may have been due to students' comfort level with text and additional time needed to complete assignments in a non-text format. Incorporation of other UDL approaches should be studied to determine the efficacy of using additional teaching techniques.

No teaching strategy or instruction works perfectly for every student. Although use of alternative formats can be time consuming and there are hurdles to overcome, instructors are able to potentially help more students attain higher levels of learning by using some if not all of the strategies addressed in this research. 


\section{Reaching Students in Online Courses Using Alternative Formats \\ Fidaldo and Thormann}

\section{References}

Allen, I.E., \& Seaman, J. (2013). Changing course:Ten years of tracking online education in the United States (Report No. 10). Babson Park, MA: Babson Survey Research Group and Quahog Research Group, LLC.

Aragon, S. R., Johnson, S. D., \& Shaik, N. (2002). The influence of learning style preferences on student success in online versus face-to-face environments. The American Journal of Distance Education, 16(4), 227-243.

Baldiris N., Silvia , Z., Panagiotis, F. G., Ramon, S., \& Demetrios G. (2016). Developing teachers' competences for designing inclusive learning experiences. Journal of Educational Technology \& Society, 19(1), 17-27.

Center for Applied Special Technology [CAST] (2014). What is universal design for learning? Wakefield, MA: Center for Applied Special Technology. Retrieved from http://www.udlcenter.org/aboutudl/whatisudl

Chita-Tegmark, M., Gravel, J. W., Serpa, M. D. B., Domings, Y., \& Rose, D. H. (2011-2012). Using the universal design for learning framework to support culturally diverse learners. Journal of Education, 192(1), 17-22.

Cook, V. (2012). Learning everywhere, all the time. Delta Kappa Gamma Bulletin, 78(3), 48-51.

Dahl, J. (2005). Apply universal design for more effective courses. Distance Education Report, 9(6), 2-6.

Dell, C. A., Dell, T. F., \& Blackwell, T. L. (2015). Applying universal design for learning in online courses: Pedagogical and practical considerations. The Journal of Educators Online, 13(2), 166-192.

Edyburn, D. L (2010). Would you recognize universal design for learning if you saw it? Ten propositions for new directions for the second decade of UDL. Learning Disability Quarterly, 33(1)33-41.

Evans, N. (2008). Theoretical foundations of universal instructional design. In J. L. Higbee \& E. Goff (Eds.), Pedagogy and student services for institutions transformation: Implementing universal design in higher education (pp. 11-24). Minneapolis, MN: University of Minnesota, Center for Research on Developmental Education and Urban Literacy, College of Education and Human Development.. Retrieved from http://www.cehd.umn.edu/passit/docs/PASS-ITBook.pdf

Hashey, A. I., \& Stahl, S. (2014). Making online learning accessible for students with disabilities. Teaching Exceptional Children, 46(5)70-78. DOI: 10.1177/0040059914528329.

He, Y. (2014). Universal design for learning in an online teacher education course: Enhancing learners' confidence to teach online. MERLOT Journal of Online Learning and Teaching, $10(2), 283-298$. 


\section{Reaching Students in Online Courses Using Alternative Formats Fidaldo and Thormann}

Higbee, J. L., Lee, P. H., Bardill, J. R., \& Cardinal, H. (2008). Student evaluations of the effectiveness of implementing universal instructional design. In J. L. Higbee, \& E. Goff (Eds.), Pedagogy and student services for institutional transformation: Implementing universal design in higher education (pp. 367-376). Minneapolis, MN: University of Minnesota, Center for Research on Developmental Education and Urban Literacy, College of Education and Human Development. Retrieved from http://www.cehd.umn.edu/passit/docs/PASS-IT- Book.pdf

Moorefield-Lang, H., Copeland, C. A., \& Haynes, A. (2016). Accessing abilities: Creating innovative accessible online learning environments and putting quality into practice. Education for Information, 32(1), 27-33. doi:10.3233/EFI-150966

Morgan, R. M. (2015). CAMMO (Creating accessible material in Microsoft Office): Developing an Atmosphere of Accessibility Through Training. Proceedings of the 2015 ACM Annual Conference on SIGUCCS, 11-15. doi:10.1145/2815546.2815566.

Passman, T. \& Green, R.A. (2009). Start with the syllabus: Universal design from the top, Journal of Access Services, 6(1-2), 48-58.

Rogowsky, B. A., Calhoun, B. M., \& Tallal, P. (2015). Matching learning style to instructional method: Effects on comprehension. Journal of Educational Psychology, 107(1), 64-78. doi:10.1037/aoo37478

Rose, D., \& Meyer, A. (2002). Teaching every student in the digital age: Universal design for learning. Alexandria, VA: Association for Supervision and Curriculum Development..

Scott, L. A., Temple, P., \& Marshall, D. (2015). UDL in online college coursework: Insights of infusion and educator preparedness. Online Learning, 19(5), 99-120.

Senge, J.C., \& Dote-Kwan, J. (1995). Information accessibility in alternative formats in postsecondary education. Journal of Visual Impairment \& Blindness. 89(2), 120 - 129.

Sims, R, Dobbs, G., \& Hand, T. (2002). Enhancing quality in online learning: Scaffolding planning and design through proactive evaluation. Distance Education, 23( 2), 135-148. DOI: 10.1080/0158791022000009169.

Tobin, T. J. (2014). Increase online student retention with universal design for learning. Quarterly Review of Distance Education, 15(3), 13-24.

Saeed, N., Yang, Y. \& Sinnappan, S. (2009). Emerging web technologies in higher education: A case of incorporating blogs, podcasts and social bookmarks in a web programming course based on students' learning styles and technology preferences. Journal of Educational Technology \& Society, 12(4), 98-109.

Thormann, J. (2013a). Research and practice: Incorporating UDL strategies in online teaching. Paper presented at the MACTE Conference: Teaching All Learners: UDL and Assistive Technology, Sturbridge, MA. 


\section{Reaching Students in Online Courses Using Alternative Formats \\ Fidaldo and Thormann}

Thormann, J. (2013b). Incorporation of universal design for learning (UDL) strategies in teaching online. Paper presented at the Community of Scholars day at Lesley University, Cambridge, MA.

Thormann, J., \& Zimmerman, I. K. (2012). The complete step-by-step guide to designing and teaching online courses. New York: Teachers College Press at Columbia University.

Vásquez, R. (2005). Save time by creating multiple formats from a single content source. Online Classroom, 5-5.

Van Rooij, S. W., \& Zirkle, K. (2016). Balancing pedagogy, student readiness and accessibility: A case study in collaborative online course development. The Internet and Higher Education, 28, 17.

Zacharis, N. Z. (2011).The effect of learning style on preference for web-based courses and learning outcomes. British Journal of Educational Technology, 42(5),790-80o. DOI: 10.1111/j.14678535.2010.01104.x.

\section{Athabasca \\ University}

cC) (†) 